\title{
Novel Ultrathin Films Based on a Blend of PEG- $b-P C L$ and PLLA and Doped with ZnO Nanoparticles
}

\author{
Lorenzo Vannozzi, Pedro Gouveia, Pasqualantonio Pingue, Claudio Canale, and Leonardo Ricotti* \\ Cite This: ACS Appl. Mater. Interfaces 2020, 12, 21398-21410 \\ Read Online
}

ABSTRACT: In this paper, a novel nanofilm type is proposed based on a blend of poly(ethylene glycol)-block-poly( $\varepsilon$-caprolactone) methyl ether (PEG-b-PCL) and poly(L-lactic acid), doped with zinc oxide nanoparticles ( $\mathrm{ZnO} \mathrm{NPs}$ ) at different concentrations $(0.1,1$, and $10 \mathrm{mg} / \mathrm{mL})$. All nanofilm types were featured by a thickness value of $\sim 500 \mathrm{~nm}$. Increasing $\mathrm{ZnO} \mathrm{NP}$ concentrations implied larger roughness values $(\sim 22 \mathrm{~nm}$ for the

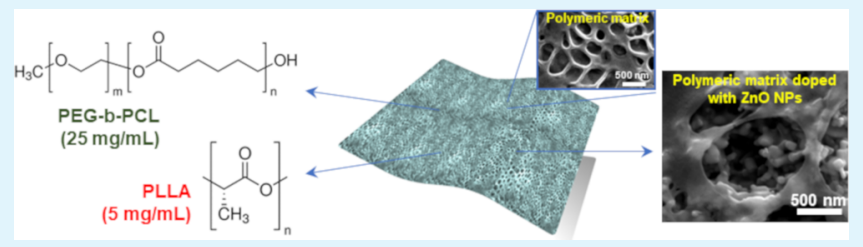
bare nanofilm and $\sim 67 \mathrm{~nm}$ for the films with $10 \mathrm{mg} / \mathrm{mL}$ of NPs), larger piezoelectricity (average $d_{33}$ coefficient for the film up to $\sim 1.98 \mathrm{pm} / \mathrm{V}$ ), and elastic modulus: the nanofilms doped with 1 and $10 \mathrm{mg} / \mathrm{mL}$ of NPs were much stiffer than the nondoped controls and nanofilms doped with $0.1 \mathrm{mg} / \mathrm{mL}$ of NPs. The ZnO NP content was also directly proportional to the material melting point and crystallinity and inversely proportional to the material degradation rate, thus highlighting the stabilization role of ZnO particles. In vitro tests were carried out with cells of the musculoskeletal apparatus (fibroblasts, osteoblasts, chondrocytes, and myoblasts). All cell types showed good adhesion and viability on all substrate formulations. Interestingly, a higher content of $\mathrm{ZnO}$ NPs in the matrix demonstrated higher bioactivity, boosting the metabolic activity of fibroblasts, myoblasts, and chondrocytes and enhancing the osteogenic and myogenic differentiation. These findings demonstrated the potential of these nanocomposite matrices for regenerative medicine applications, such as tissue engineering.

KEYWORDS: nanocomposite, thin film, piezoelectric scaffold, zinc oxide, regenerative medicine

\section{INTRODUCTION}

Polymeric ultrathin films (also named nanofilms or nanosheets) recently emerged as novel devices suitable for a series of bioengineering applications, including tissue engineering and regenerative medicine. ${ }^{1}$ They can be considered quasitwo-dimensional (2D) structures with a sub-micrometric thickness (up to hundreds of nanometers) and a larger surface area (up to several square centimeters). These geometrical features combined with their tailored surface chemistry make nanofilms amenable for a broad range of applications. ${ }^{2}$

Indeed, they have been used as components of chemical/ biological sensors and nanoelectronic devices, ${ }^{3}$ as ultraconformable circuits and electrodes, ${ }^{4}$ as well as encapsulation systems for hydrogen storage materials. ${ }^{5}$ However, these structures have recently demonstrated a great potential also in the biomedical field. ${ }^{6-8}$

Takeoka and colleagues formerly exploited the large contact area of biodegradable nanosheets to develop nanoadhesive plasters showing several advantages for surgical dressing. ${ }^{9}$ Polymeric nanofilms have also been widely used for developing smart drug delivery systems: ${ }^{10,11}$ small drugs, proteins, or nucleic acids can be efficiently embedded in ultrathin matrices by adsorption, chemical binding, or physical confinement. Such elements can be released through simple diffusion mechanisms or by exploiting triggering effects, ${ }^{12-14}$ Another widely employed medical application concerns implant surface coating: van den Beucken and colleagues reported the efficacy of DNA-based coatings on titanium, obtained via an electrostatic self-assembly technique. ${ }^{15}$ Nichols et al. demonstrated that degradable nano-thick coatings enhanced the bonding strength with nanocrystalline hydroxyapatite, with promising applications in bone regeneration. ${ }^{16}$ Recently, Kam and colleagues highlighted the importance of nanocoatings provided with specific topographies to properly modulate protein adsorption at the surface of the implant and the expression of factors associated with body fibrotic response. ${ }^{17}$

One of the most intriguing biomedical applications of nanofilms concerns their close interaction with living cells and their capability to influence key cell processes, such as adhesion, proliferation, and differentiation. Polymeric ultrathin films are particularly suitable to this purpose, thanks to their high tailorability in terms of mechanical properties, surface chemistry, surface electrical charges, and overall matrix flexibility. Single-layer and multilayer nanofilms have been recently proposed as innovative platforms in the fields of

Received: January 4, 2020

Accepted: April 17, 2020

Published: April 17, 2020 
Table 1. Influence of Different ZnO NP Contents on the Thickness of PEG- $b$-PCL/PLLA Nanofilms

\begin{tabular}{lcccc}
\multicolumn{1}{c}{ sample } & ZnO NP concentration $(\mathrm{mg} / \mathrm{mL})$ & ZnO NP weight fraction $(\%)$ & ZnO NP volume fraction $(\%)$ & thickness $(\mathrm{nm})$ \\
\hline PEG- $b$-PCL/PLLA & 0 & 0 & 0 \\
PEG- $b$-PCL/PLLA-0.1 & 0.1 & 0.33 & 20 \\
PEG- $b$-PCL/PLLA- 1 & 1 & 3.23 & 0.07 \\
PEG- $b$-PCL/PLLA-10 & 10 & 25 & 0.68 \\
\end{tabular}
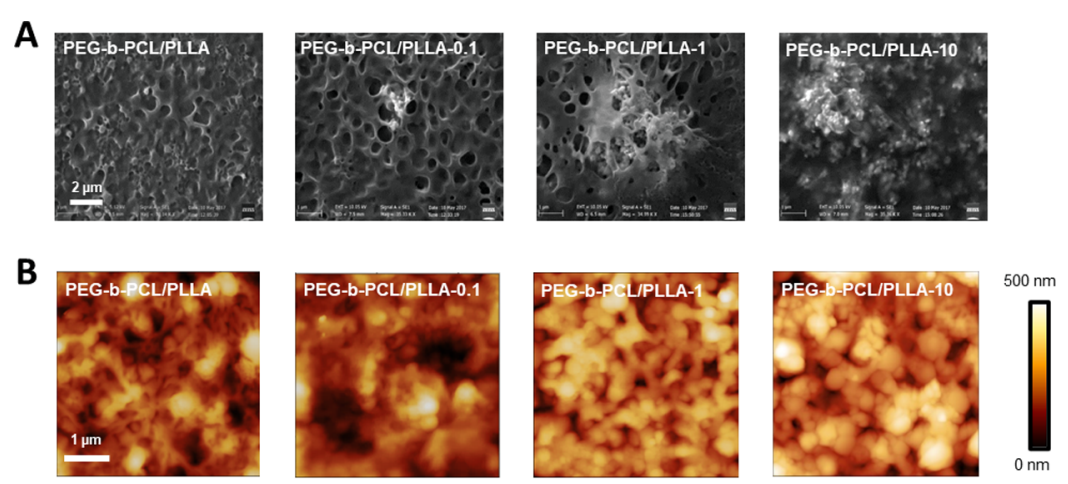

C

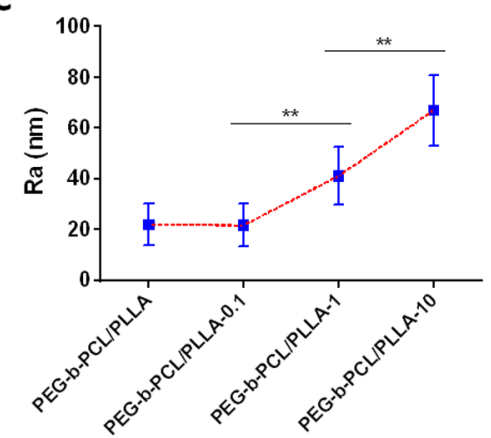

D

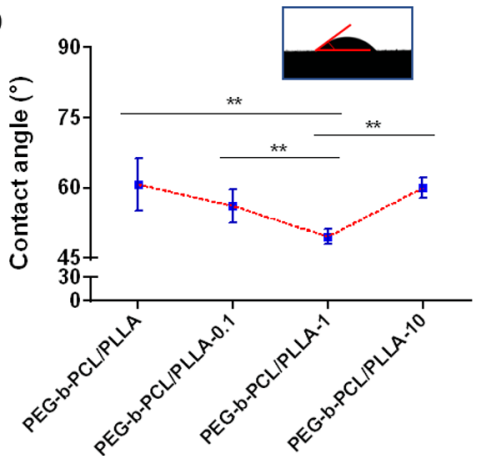

E

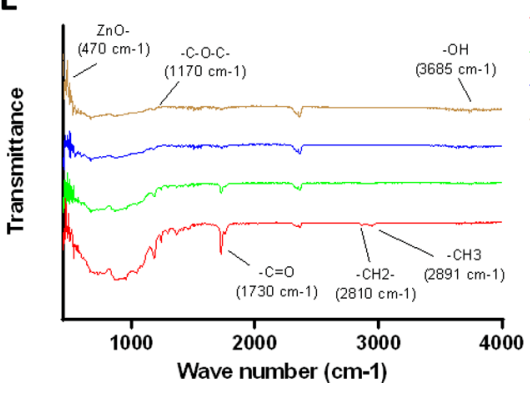

- PEG-b-PCL/PLLA

- PEG-b-PCL/PLLA-0.1

- PEG-b-PCL/PLLA-1

- PEG-b-PCL/PLLA-10

Figure 1. Topographical surface features described by (A) SEM and (B) AFM images of PEG-b-PCL/PLLA nanofilms provided with different $\mathrm{ZnO}$ NP concentrations. (C) Average roughness and (D) contact angle values for the different nanofilm types. (E) Results of the FTIR analysis. $* * p<0.01$.

regenerative medicine and tissue engineering. ${ }^{1,18,19}$ To this aim, polyelectrolyte multilayer films have been tested as tools for mechanosensitivity studies on mammalian cells, ${ }^{20}$ also evaluating the role of gelatin- and fibronectin-based coatings. ${ }^{21}$ Single-layer nanofilms have also been tested with a number of normal and cancer cell types, with the aim of exploiting the peculiar mechanical, ${ }^{22,23}$ chemical, $^{24-26}$ and topographical ${ }^{27}$ nanosheet features in order to influence cell processes or to promote certain stem cell fates. ${ }^{28}$

As known, cell behavior is strongly influenced by nanoscale chemical-physical patterns and cues, which constitute an instructive environment able to regulate cell adhesion, orientation and motility, cytoskeletal condensation, and modulation of intracellular signalling pathways that control protein synthesis. ${ }^{29,30}$ Composite ultrathin films constituted by a polymeric matrix with embedded polymeric or nonpolymeric nanomaterials represent interesting devices, able to combine the unique properties of nanofilms with additional cues provided by the presence of nanofillers. Few examples of such systems interfaced with living cells have been reported in the recent literature: hybrid organic-inorganic films were reviewed by Podsiadlo and colleagues, highlighting the potential of thin structures made of a polymer/clay doped with nanotubes for a series of applications, including biological ones. ${ }^{31}$ Ventrelli et al. demonstrated that the incorporation of magnetic nanoparticles (NPs) within poly(lactic acid) nanofilms allowed to modulate film roughness and wettability, thus deeply influencing the adhesion and proliferation of $\mathrm{H} 9 \mathrm{c} 2$ 
Table 2. Contact Angle Measurements with Water, Ethylene Glycol, Hexane, and Average Values of the Surface Energy for Each Nanofilm Type

\begin{tabular}{|c|c|c|c|c|}
\hline sample & $\begin{array}{l}\text { contact angle with water } \\
\text { (deg) }\end{array}$ & $\begin{array}{l}\text { contact angle with ethylene glycol } \\
\text { (deg) }\end{array}$ & $\begin{array}{l}\text { contact angle with hexane } \\
\text { (deg) }\end{array}$ & $\begin{array}{c}\text { surface energy }\left(\mathrm{mJ} / \mathrm{m}^{2}\right) \text { - average } \\
\text { value }\end{array}$ \\
\hline PEG- $b$-PCL/PLLA & $60.77 \pm 5.61$ & $10.40 \pm 1.17$ & $51.56 \pm 4.04$ & 25.25 \\
\hline PEG- $b$-PCL/PLLA-0.1 & $56.21 \pm 3.47$ & $9.64 \pm 1.15$ & $52.48 \pm 3.95$ & 40.86 \\
\hline PEG- $b$-PCL/PLLA-1 & $49.65 \pm 1.77$ & $10.46 \pm 1.24$ & $51.29 \pm 4.09$ & 48.30 \\
\hline PEG- $b$-PCL/PLLA-10 & $60.10 \pm 2.24$ & $10.58 \pm 1.75$ & $56.10 \pm 3.11$ & 38.69 \\
\hline
\end{tabular}

myoblasts. $^{32}$ Uskokovic and colleagues recently developed poly( $\varepsilon$-caprolactone) (PCL) thin films doped with hydroxyapatite. The nanoscale topographical features of these devices influenced the viability, proliferation, migration, and osteogenesis of fibroblastic and osteoblastic MC3T3-E1 cells. ${ }^{33}$

To the best of our knowledge, no insights have been reported on poly(ethylene glycol)-block-PCL (PEG-b-PCL) ultrathin films doped with zinc oxide $(\mathrm{ZnO})$ nanomaterials. PCL is a biocompatible and biodegradable polymer extensively studied and used in drug delivery and tissue engineering. ${ }^{34}$ It can be modulated in its chemical-physical properties by blending or copolymerizing it with other polymers. In particular, PEG-b-PCL block amphiphilic copolymers show interesting properties because of the hydrophilic behavior of PEG chains associated with PCL hydrophobicity. PEG- $b$-PCL structures have been mostly exploited to build micelles for drug delivery so far. ${ }^{35-37}$ Recently, amphiphilic block copolymers based on PCL and poly(L-lactic acid) (PLLA) have been attracting interest for tissue engineering applications. ${ }^{38}$ On the other hand, $\mathrm{ZnO}$ nanomaterials are inorganic structures featured by low toxicity ${ }^{39}$ and strong piezoelectric properties. $^{40}$ Thus, they are promising in view of a nanomaterial-mediated stimulation of cells and tissues. ${ }^{41}$

In this paper, we report for the first time the opportunity to build robust ultrathin films based on a blend of PEG- $b$-PCL and PLLA and doped with $\mathrm{ZnO}$ nanopowder (NPs), exploiting the miscibility of the amorphous regions of PLLA with the hydrophilic PEG domains of PEG- $b$-PCL ${ }^{42}$ and by using $\mathrm{ZnO}$ NPs as stabilizers. We analyzed the effect of three different $\mathrm{ZnO}$ concentrations within the polymeric matrix in terms of morphological, piezoelectric, mechanical, and chemical properties. Finally, in vitro results were carried out to demonstrate the biocompatibility and bioactivity of these materials with fibroblasts, osteoblasts, myoblasts, and chondrocytes.

\section{RESULTS AND DISCUSSION}

Ultrathin Film Fabrication and Morphological Characterization. PEG- $b$-PCL/PLLA blend nanofilms doped with increasing concentrations of $\mathrm{ZnO}$ NPs were fabricated through spin coating, achieving a thickness value of $\sim 500 \mathrm{~nm}$ for all material formulations (Table 1 ).

The addition of $\mathrm{ZnO}$ NPs did not significantly influence the overall film thickness, but it implied modifications of other material properties such as surface morphology, roughness, piezoelectricity, and stiffness. Figure 1A shows scanning electron microscopy (SEM) microimages of the different nanofilm formulations. It can be observed that increasing amounts of $\mathrm{ZnO}$ NPs led to a less porous surface texture. This was probably due to the relatively fast dichloromethane evaporation after the spin-coating phase that determined a texture with a higher porosity for the formulations provided with a smaller amount of ZnO NPs. Energy-dispersive X-ray (EDX) spectroscopy revealed that the $\mathrm{ZnO}$ NPs were homogeneously dispersed in the polymeric matrices for all the doped formulations, with only a few aggregates of NPs observed (Figure S1). The morphology of ZnO NPs was not regular, and their size was typically smaller than $100 \mathrm{~nm}$, as shown in Figure S2.

The atomic force microscopy (AFM) images shown in Figure $1 \mathrm{~B}$ confirmed the observations made on the porosity through SEM imaging. The surface roughness analysis revealed that average roughness $\left(R_{\mathrm{a}}\right)$ values considerably increased by increasing the nanofiller content, ranging from $22.11 \pm 8.29$ $\mathrm{nm}$ for the bare nanofilm up to $67.08 \pm 13.91 \mathrm{~nm}$ for the PEG$b$-PCL/PLLA-10 sample (Figure 1C). By increasing the nanofiller content, a more compact surface texture emerged, probably due to a different interaction between the NPs and the polymeric matrix that influenced the solvent evaporation dynamics. Despite that, these samples were featured by a higher roughness. These outcomes are in line with other reports in which the addition of nanofillers increased the overall roughness of the polymeric matrix. ${ }^{43,44}$

The contact angle values reported in Figure $1 \mathrm{D}$ highlighted a hydrophilic behavior for all formulations, essentially due to the presence of PEG domains that counteract the hydrophobicity of both PCL and PLLA. The contact angle values decreased from $60.76 \pm 5.61^{\circ}$ for the bare nanofilm down to $49.65 \pm$ $1.67^{\circ}$ for the PEG- $b$-PCL/PLLA-1 formulation, with an inversely proportional relationship between contact angle values and roughness. ${ }^{45}$ Interestingly, higher values (60.09 \pm $2.24^{\circ}$ ) were found for the PEG- $b$-PCL/PLLA-10 formulation, probably due to the larger amount of hydrophobic $\mathrm{ZnO}$ which counteracted the hydrophilicity of PEG. The achievement of an overall hydrophilic behavior is interesting in view of an interaction of these materials with immune cells. In fact, hydrophilic materials trigger lower immune responses in comparison to their hydrophobic counterparts, regulating the macrophage behavior in a different way. ${ }^{46,47}$

Contact angle measurements were also performed on fluids different from water, namely, ethylene glycol (polar) and hexane (apolar), for the evaluation of the surface energy of each material formulation according to the van OssChaudhury-Good theory. ${ }^{48}$ Results are summarized in Table 2 .

Assuming the well-known parameters of surface tension $\left(\gamma_{1 \mathrm{~s}}\right)$ and the Lifshitz-van der Waals components of surface energy of the mentioned liquids $\left(\gamma_{1}^{+}, \gamma_{1}^{-}, \gamma_{1}^{\mathrm{LW}}\right)$, it is possible to obtain the energy parameters associated with the solid surface $\left(\gamma_{S}^{+}, \gamma_{S}^{-}\right.$, $\left.\gamma_{\mathrm{S}}^{\mathrm{LW}}\right)$. According to the van Oss-Chaudhury-Good theory, the surface energy of a solid surface derives from the combination of the Lifshitz-van der Waals and the acid-based components of the surface energy. Table 2 also reports the average values of the surface energy for each material formulation.

Such values are similar to the proper values of PCL, PLLA, $\mathrm{PEG}$, and $\mathrm{ZnO}$, which show surface energy values between 35 and $50 \mathrm{~mJ} / \mathrm{m}^{2}$. ${ }^{4-51}$ PEG- $b$-PCL/PLLA- 1 has the higher 
A

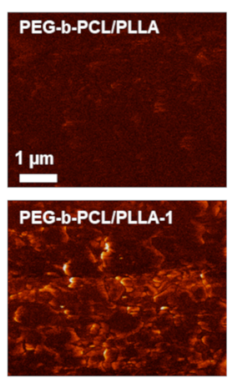

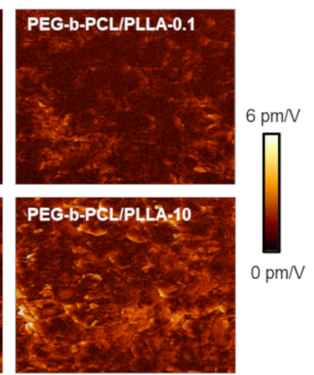

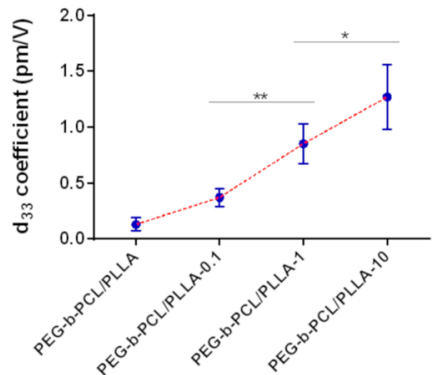

Figure 2. (A) Piezoelectric force microscopy maps of nanofilms with different $\mathrm{ZnO} \mathrm{NP}$ contents; (B) $d_{33}$ coefficients, calculated from the signal amplitude values of the PFM scans. ${ }^{*} p<0.05, * * p<0.01$.

surface energy being the most hydrophilic combination, while PEG- $b$-PCL/PLLA-10 is slightly hydrophobic against apolar solvents (e.g., hexane). Our results show that the achievement of a higher porous texture, as for PEG-b-PCL/PLLA, does imply lower surface energies. When NPs are added within the polymeric blend, their interaction with the matrix allowed to increase the surface energy, thus leading to a lower porous but rougher texture while increasing the concentration. Interestingly, the formulation with the highest content of NPs (PEG- $b$ PCL/PLLA-10) shows a slightly lower average value compared with the other doped preparations. This is probably due to the higher surface roughness that may decrease the surface energy of the solid surface, thus reducing the wettability of the liquids because of the elevated presence of hydrophobic $\mathrm{ZnO}$ NPs.

The interaction between the filler and the polymeric blend has been further investigated through Fourier transform infrared spectroscopy (FTIR) analysis (Figure 1E). Results highlight that all the material formulations showed the characteristic peaks of PEG, PCL, and PLLA. The peak at $3685 \mathrm{~cm}^{-1}$ corresponds to the $-\mathrm{OH}$ stretching vibration, while the peaks at 2891 and $2810 \mathrm{~cm}^{-1}$ are related to the $\mathrm{C}-\mathrm{H}$ stretching vibrations of $-\mathrm{CH}_{3}$ and $-\mathrm{CH}_{2}$ groups, respectively. Then, other visible peaks are attributed to the carbonyl group $-\mathrm{C}=\mathrm{O}$ stretching vibration at $1730 \mathrm{~cm}^{-1}$, typical of ester groups of PLLA, and the $-\mathrm{C}-\mathrm{O}-\mathrm{C}-$ group stretching vibration at $1170 \mathrm{~cm}^{-1} .52$ The presence of $\mathrm{ZnO} N P s$ is revealed by a higher peak at $470 \mathrm{~cm}^{-1}$, which corresponds to the stretching of $\mathrm{Zn}-\mathrm{O}$ bonds. ${ }^{53}$ The polymeric matrices doped with $\mathrm{ZnO}$ NPs do not show a dramatic shift in the position of the peaks, compared to the bare PEG- $b$-PCL/PLLA blend, although the intensity of some peaks is clearly altered by $\mathrm{ZnO}$ NPs. For example, the $-\mathrm{CH}_{2},-\mathrm{CH}_{3}$, and $\mathrm{C}=\mathrm{O}$ stretching appears at different intensities, thus corroborating a possible change in polymeric chain interactions, such as a lower polymeric chain vibration, because of the presence of $\mathrm{ZnO}$. Furthermore, secondary forces such as weak hydrogen bonds may also play a role in the interaction between $\mathrm{ZnO}$ NPs and the polymeric matrix. ${ }^{54}$

Piezoelectric Characterization. The piezoelectric analysis of samples showed that PEG- $b$-PCL/PLLA matrices increased their piezoelectric coefficients corresponding to an increase of $\mathrm{ZnO} \mathrm{NP}$ content (Figure 2A).

By considering all the timely measurements in each map acquired through piezoresponse force microscopy (PFM), the average $d_{33}$ piezoelectric coefficient ranged from $0.21 \pm 0.09$ $\mathrm{pm} / \mathrm{V}$ (PEG- $b$-PCL/PLLA) to $1.98 \pm 0.46 \mathrm{pm} / \mathrm{V}$ (PEG- $b$ PCL/PLLA-10) (Figure 2B). These values are average ones: film piezoelectricity showed peak values up to $6 \mathrm{pm} / \mathrm{V}$ in areas corresponding to the $\mathrm{ZnO}$ NPs. The piezoelectricity of the proposed nanocomposite films opened intriguing opportunities. ${ }^{55}$ Indeed, for example, the piezoelectric coefficient of the bone can reach peak values up to $8 \mathrm{pm} / \mathrm{V},{ }^{56}$ close to the peak values recorded on the $\mathrm{ZnO}$-doped nanofilms.

Mechanical Characterization. The analysis of the sample mechanical properties obtained through the strain-induced elastic buckling instability for mechanical measurements (SIEBIMM) test (Figure 3A) showed that the nanofilm elastic moduli ranged from a median value of $50.62 \mathrm{MPa}$ (PEG- $b$ $\mathrm{PCL} / \mathrm{PLLA}$ ) up to $231.1 \mathrm{MPa}$ (PEG- $b$-PCL/PLLA-10) (Figure 3B).

These results highlighted a link between the $\mathrm{ZnO}$ content and the overall nanofilm rigidity. Statistical analyses revealed that nondoped nanofilms and nanofilms doped with $0.1 \mathrm{mg} /$ $\mathrm{mL}$ of $\mathrm{ZnO}$ NPs showed the same elastic modulus. However, nanofilms doped with 1 and $10 \mathrm{mg} / \mathrm{mL}$ were much stiffer. In general, these observations are in agreement with the results found with other nanocomposite materials, in which the filler concentration improved the matrix mechanical properties, until reaching a certain plateau. ${ }^{57-59}$

Degradation Analysis. The analysis of the sample degradation rate showed that the weight loss due to hydrolytic degradation was inversely proportional to the content of NPs (Figure 4A).

After a period of 16 weeks, an average weight reduction of 54.2, 48.0, and 33.2\% was observed for PEG- $b$-PCL/PLLA, PEG- $b$-PCL/PLLA-0.1, and PEG- $b$-PCL/PLLA-1, respectively. Interestingly, the samples with the highest NP concentration $(10 \mathrm{mg} / \mathrm{mL})$ resulted in an average weight above $100 \%$ $(\sim 113.0 \%)$. Such a result can be explained observing the intrinsic high surface energy of $\mathrm{ZnO}$ NPs. Indeed, this promoted salt precipitation on the nanofilm surface, which compensated the weight loss. This was confirmed by the SEM analysis of the nanofilm surface after 16 weeks, in which salt crystals are clearly visible (Figure 4B).

Bioresorbability is an important feature of biomaterials. ${ }^{60}$ Both PCL and PLLA are featured by degradation times exceeding 24 months, ${ }^{61}$ while PEG, being water-soluble, may significantly decrease the degradation time of the composite films. A high content of $\mathrm{ZnO}$ NPs improved the composite resistance to erosion, enhancing the biomaterial integrity.

The thermal properties of each formulation were analyzed to better ascertain the interaction between $\mathrm{ZnO}$ NPs and the polymeric blend (Figure $4 \mathrm{C}$ ). The melting curves showed an average melting peak that ranged from an average value of 58.1 ${ }^{\circ} \mathrm{C}$ (PEG- $b$-PCL/PLLA) to $59.3{ }^{\circ} \mathrm{C}$ (PEG- $b$-PCL/PLLA-10). This trend can be attributed to an overall increase of the interfacial interactions between $\mathrm{ZnO}$ NPs and the polymeric matrix. ${ }^{62}$ This implies a higher crystallinity degree that varied 
A

PEG-b-PCL/PLLA
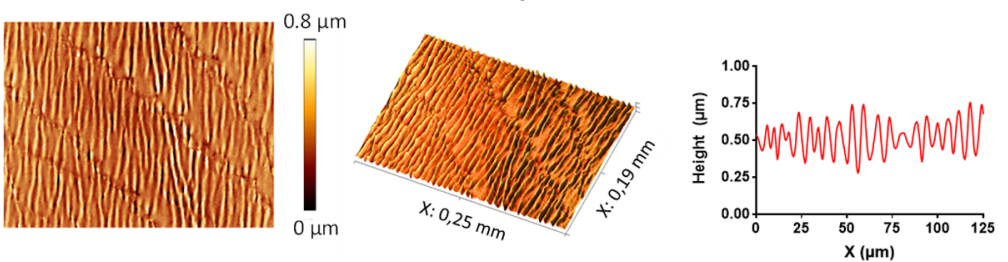

PEG-b-PCL/PLLA-0.1
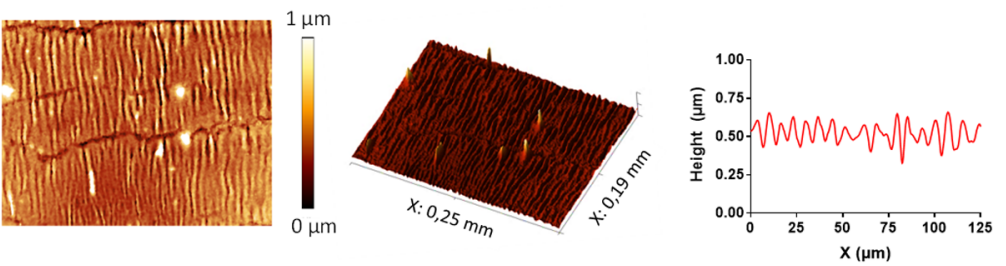

PEG-b-PCL/PLLA-1
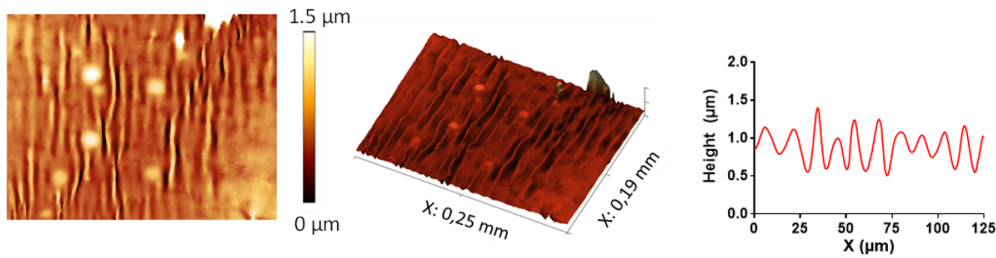

PEG-b-PCL/PLLA-10
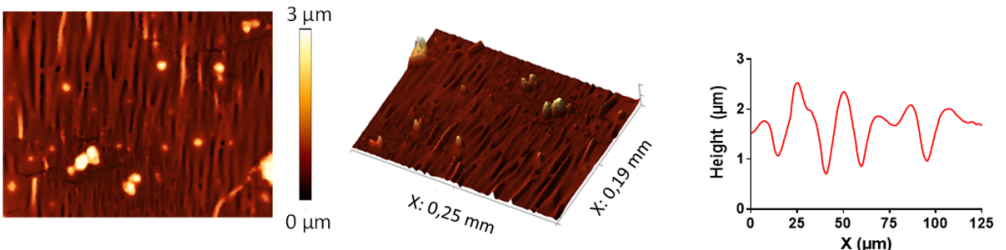

B

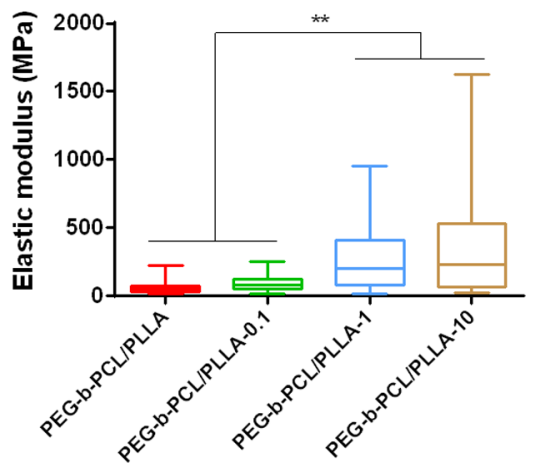

Figure 3. (A) Analysis of the 3D profiles acquired through the optical profiler of each nanofilm formulation (left) and a corresponding height profile analysis (right) after performing the SIEBIMM test. (B) Elastic moduli represented through box plots $(2.5-97.5$ percentile). $* * p<0.01$.

from $66.1 \%$ (PEG- $b$-PCL/PLLA) to $76.6 \%$ (PEG- $b$-PCL/ PLLA-10). This can also be correlated with the higher stiffness values (Figure 3 ), as well as with a longer-term stability ${ }^{63,64}$ (Figure 4A).

In vitro tests: interaction with fibroblasts, osteoblasts, myoblasts, and chondrocytes.

Figure 5 summarizes the results of the interaction between normal human dermal fibroblasts (nHDFs) and the different nanofilm types in terms of cell viability (Figure 5A) and metabolic activity over 3 days (Figure 5B). Live/dead images at $24 \mathrm{~h}$ showed a good level of nHDF viability on the different substrates, with almost no dead/necrotic cells. nHDFs effectively spread on the nanofilm surface, with no appreciable differences in terms of morphology, on the different sample types.

The cell metabolic activity increased day-by-day for the different samples. Interestingly, at the $24 \mathrm{~h}$ time point, the cells cultured on the samples doped with $\mathrm{ZnO}$ NPs showed a significantly higher metabolic activity with respect to those cultured on nondoped nanofilms. At the 48 and $72 \mathrm{~h}$ time points, only the PEG- $b$-PCL/PLLA-10 formulation was statistically different with respect to the bare nanofilms. These results highlight the higher bioactivity of the $\mathrm{ZnO}$ NP-doped matrices, which are able to accelerate the intra- 
A

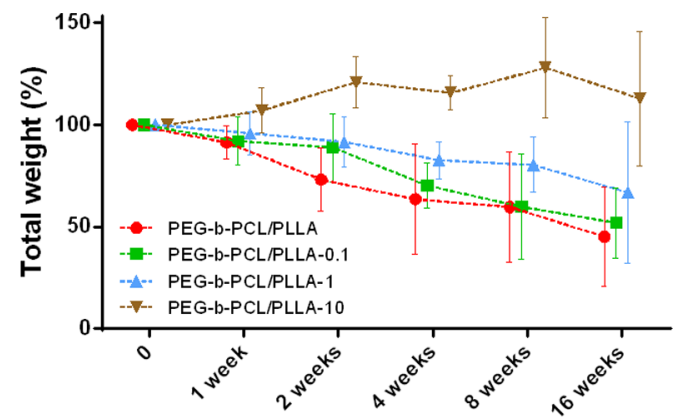

B
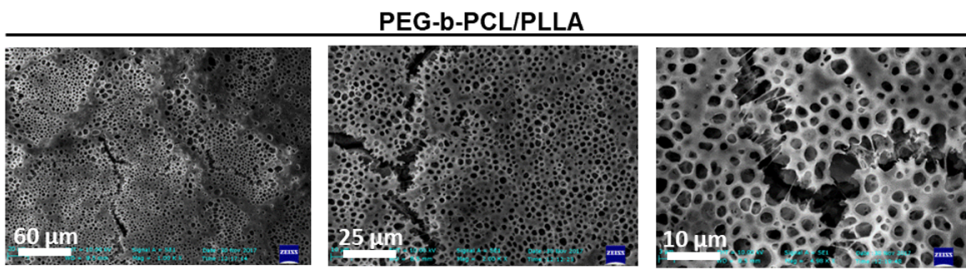

PEG-b-PCL/PLLA-10
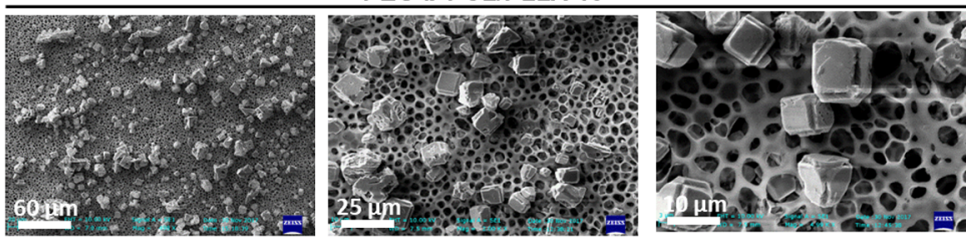

C
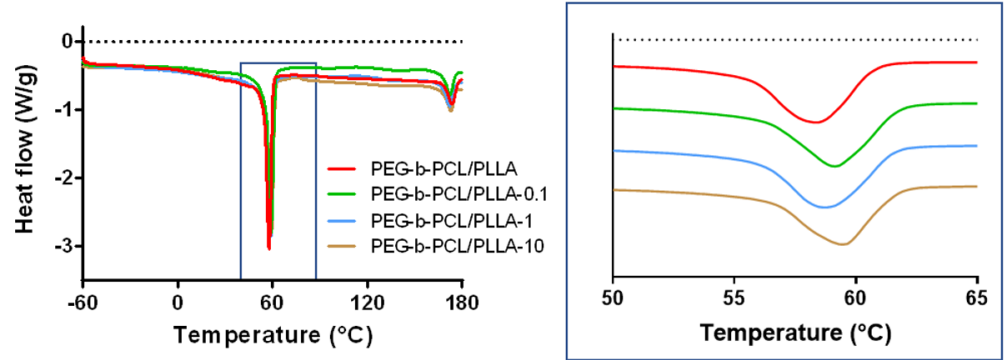

Figure 4. (A) Degradation kinetics described as the remaining sample total mass over time. (B) SEM images of two representative sample types having different $\mathrm{ZnO} N P$ contents $\left(0\right.$ and $10 \mathrm{mg} / \mathrm{mL}$ ) at different magnifications. (C) Depiction of the DSC curve between -60 and $180{ }^{\circ} \mathrm{C}$ (left) and a detail of the curve at $60^{\circ} \mathrm{C}$ (right).
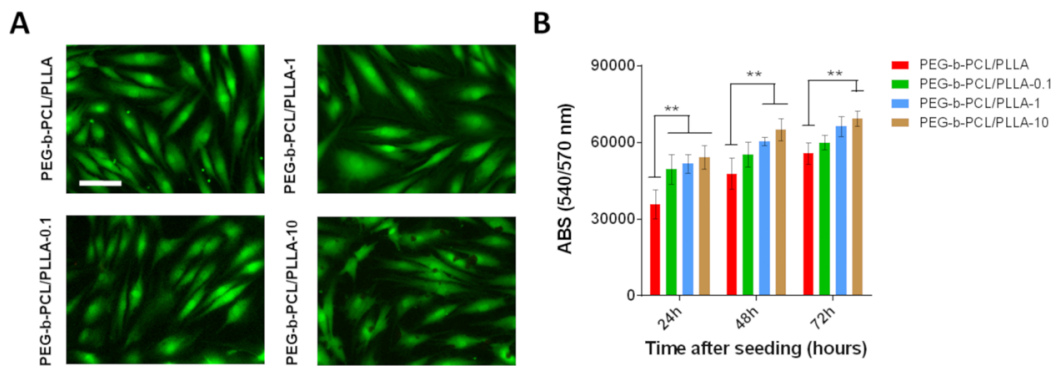

Figure 5. Interaction of the different nanofilm types with HDFs: (A) live/dead assay performed at $24 \mathrm{~h}$ after seeding (green $=$ live cells, red $=$ dead/necrotic cells). Scale bar is $50 \mu \mathrm{m}$. (B) Cell metabolic activity at days 1, 2, and 3 after seeding. **p< 0.01 .

cellular cell metabolic processes, especially at high concentrations. Previous literature evidence showed that $\mathrm{ZnO}$ NPs, dispersed in poly(vinyl chloride), decreased bacteria growth and enhanced fibroblast proliferation $18 \mathrm{~h}$ after seeding. ${ }^{65}$ In the above-mentioned study, $\mathrm{ZnO}$ NPs were used at a high concentration $(15 \% \mathrm{w} / \mathrm{w})$. In this paper, different weight fractions of NPs were tested $(0.33,3.23$, and $25 \% \mathrm{w} / \mathrm{w}$ - see
Table 1). In addition, different time points were analyzed in our study: this allowed to clarify that even a small quantity of $\mathrm{ZnO}$ NOPs has a statistically significant effect on fibroblast metabolic activity at $24 \mathrm{~h}$, while only the highest concentration still maintains a longer-term effect in the following days. In the previously mentioned study, the authors argued that substrate wettability may play a role on the different cell behavior. 
A
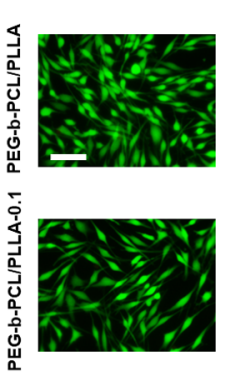

C

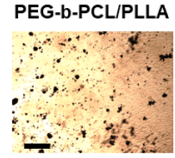

D

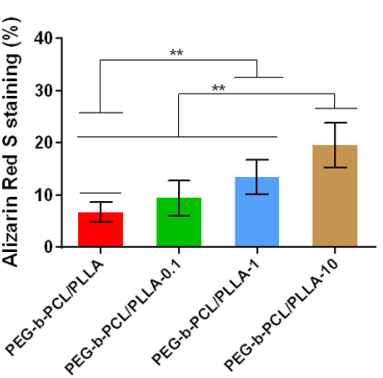

B

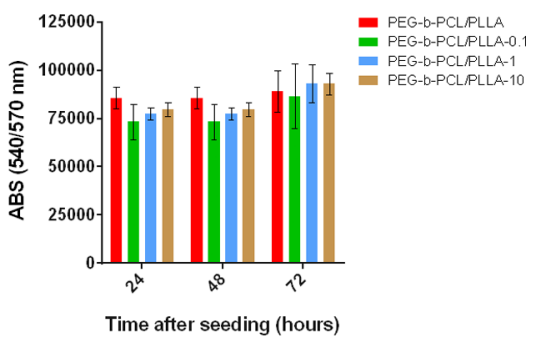

Figure 6. Interaction of the different nanofilm types with MG-63 osteoblasts: (A) live/dead assay at $24 \mathrm{~h}$ (green $=$ live cells, red $=$ dead $/ \mathrm{necrotic}$ cells). Scale bar is $50 \mu \mathrm{m}$. (B) Cell metabolic activity over 3 days. (C) Alizarin-red-S staining of MG-63 cells differentiated for 10 days on the different nanofilm formulations. Scale bar is $200 \mu \mathrm{m}$. (D) Evaluation of the area covered by calcium, estimated from the images and (E) quantified through absorbance readings. $* * p<0.01$.

A
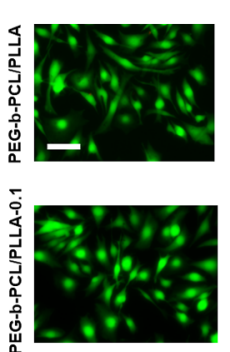

c
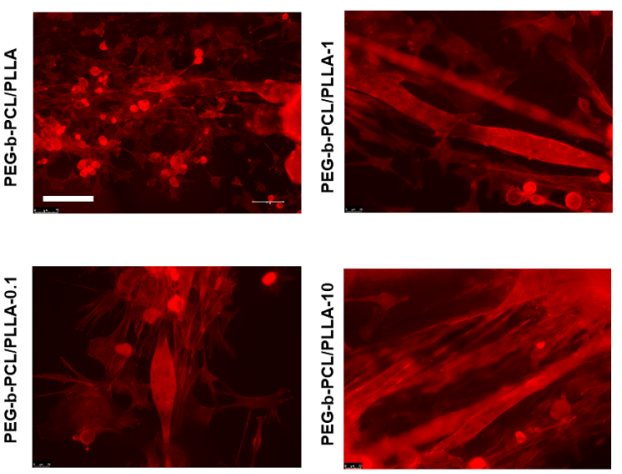

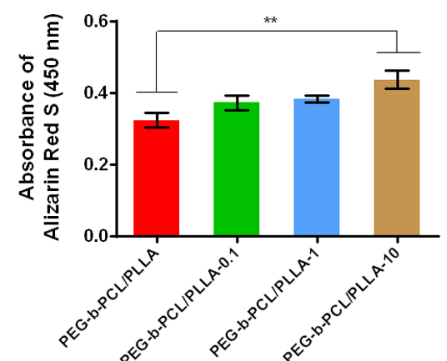

PEG-b-PCL/PLLA-1 PEG-b-PCL/PLLA-10
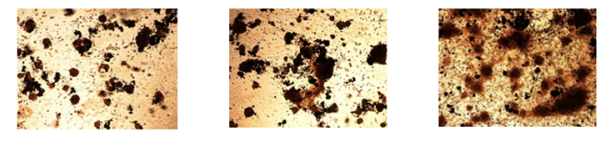

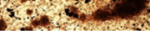


A

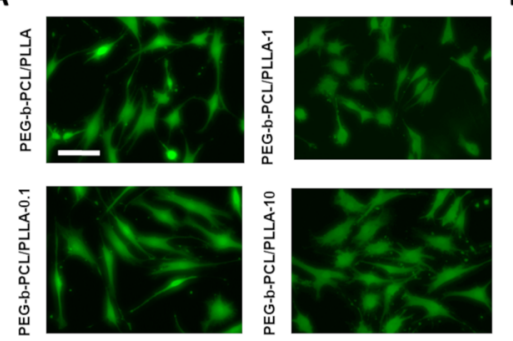

B

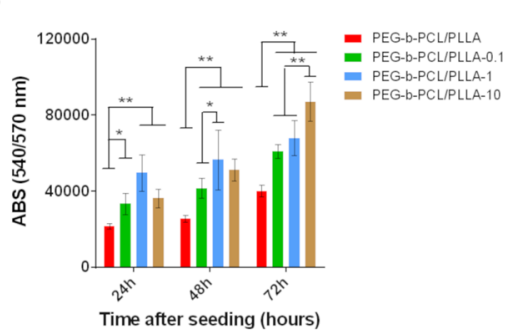

Figure 8. Interaction of the different nanofilm types with HCs: (A) live/dead assay performed at $24 \mathrm{~h}$ after seeding (green $=$ live cells, red $=$ dead/ necrotic cells). Scale bar is $50 \mu \mathrm{m}$. (B) Cell metabolic activity at days 1,2 , and 3 after seeding. $* * p<0.01, * p<0.05$.

(Figure 1D). Rather, these results can be explained by surface bioactivity enabled by the ZnO NPs, which may imply a higher protein absorption on the nanofilm surface ${ }^{66}$ that, in turn, can influence cell behavior.

Figure 6 shows the results of the interaction between MG-63 osteoblasts and the different nanofilm types in terms of viability (Figure 6A), metabolic activity over 3 days (Figure $6 \mathrm{~B})$, and calcium deposition upon differentiation for 10 days (Figure 6C-E).

Also in this case, a good cell viability emerged for all the substrates, with almost no dead/necrotic cells and with live cells showing a nicely spread shape. No statistically significant differences emerged between the different samples in terms of osteoblast metabolic activity over 3 days.

A preliminary valuation of osteoblast differentiation was also carried out by calcium assessment. Results showed that all substrates exhibited calcium formation (Figure 6C). The mineral deposition significantly increased for higher amounts of $\mathrm{ZnO}$ NPs, when compared to the bare formulation (PEG- $b$ PCL/PLLA). Calcium deposition in PEG-b-PCL/PLLA-10 samples was almost 3 times higher compared to that in the nondoped control (Figure 6D). These results were also confirmed by a quantitative analysis through absorbance readings (Figure $6 \mathrm{E}$ ) in order to exclude the possible contribution because of the affinity between $\mathrm{ZnO}$ and the Alizarin Red dye. These results confirmed that $\mathrm{ZnO}$ NPs constituted a boost in the cell differentiation phase. Calcium formation was not influenced by previous cell metabolic activity rates, being not statistically different over 3 days (Figure 6B).

This behavior may be due to different factors: the piezoelectric nature of $\mathrm{ZnO}$ (Figure 2) may promote a faster bone-like tissue maturation. Indeed, piezoelectric composites can contribute to bone remodeling and healing, while bone cells are exposed to stress ${ }^{67,68}$ and can be even remotely stimulated with ultrasound. ${ }^{69}$ Besides, zinc plays an important role in bone metabolism because its deficiency may result in bone loss. Zinc ions released from the composite nanofilm may constitute a bioactive compound that has calcium-forming abilities and is able to stimulate osteoblasts. ${ }^{70,71} \mathrm{ZnO}$ NPs may also constitute optimal nucleation sites for calcium mineralization. Furthermore, previous scientific evidence highlighted that surface roughness has an influence on osteogenic differentiation. ${ }^{72}$ The increased surface roughness of the nanocomposite substrates (Figure 1C) thus probably plays a role in the higher calcium deposition on the substrates featured by a higher content of $\mathrm{ZnO}$ NPs.

Figure 7 shows the results concerning the interaction between $\mathrm{C} 2 \mathrm{C} 12$ myoblasts and the different nanofilm types in terms of viability (Figure 7A), metabolic activity over 3 days (Figure $7 \mathrm{~B}$ ), and differentiation after 5 days (Figure $7 \mathrm{C}$ ).

The cells obtained were viable on all nanofilm formulations. No differences among the samples were found in myoblast metabolic activity after $24 \mathrm{~h}$, while at the subsequent time points (48 and $72 \mathrm{~h}$ ), the metabolic activity of the cells cultured on PEG- $b$-PCL/PLLLA-10 samples was much higher compared to that of the cells cultured on the other substrates. This behavior can be ascribed not only to a higher protein absorption because of $\mathrm{ZnO} \mathrm{NP}$ bioactivity but also to higher roughness values, which have been shown to improve $\mathrm{C} 2 \mathrm{C} 12$ proliferation. ${ }^{43,73}$

Differentiation results showed that after 5 days, the presence of $\mathrm{ZnO} \mathrm{NP}$ concentrations above $1 \mathrm{mg} / \mathrm{mL}$ allowed to obtain longer myotubes (up to $\sim 300 \mu \mathrm{m}$ ) with respect to the bare nanofilms and the nanofilms doped with $0.1 \mathrm{mg} / \mathrm{mL}$ of NPs, while the myotube width was not affected. These results suggest a relevant contribution provided by the $\mathrm{ZnO}$ NPs, which played a major role during the differentiation phase, as previously shown for MG-63 cells. The scaffold piezoelectricity may be a boosting stimulus for this phenomenon. The presence of $\mathrm{ZnO}$ within the polymeric matrix may also constitute a bioactive stimulus for the formation of more mature myotubes by providing a zinc release rate able to stimulate muscle cells to differentiate. Similar insights have been found by Trujilio et al., although a clear threshold of $\mathrm{ZnO}$ NP concentration to be introduced was not identified; ${ }^{74}$ in our study, we clarified that concentrations in the order of magnitude of $1 \mathrm{mg} / \mathrm{mL}$ or higher have significant effects on C2C12 differentiation, while smaller amounts (e.g., $0.1 \mathrm{mg} /$ $\mathrm{mL}$ ) do not considerably affect muscle cell behavior.

Figure 8 summarizes the results of the interaction between human chondrocytes (HCs) and the different nanofilm types in terms of cell viability (Figure $8 \mathrm{~A}$ ) and metabolic activity over 3 days (Figure $8 \mathrm{~B}$ ). Live/dead images at $24 \mathrm{~h}$ showed a good level of $\mathrm{HC}$ viability on the different substrates, with almost no dead/necrotic cells and no substantial differences in terms of morphology.

The cell metabolic activity increased over time for the different samples. The presence of $\mathrm{ZnO}$ NPs showed a higher cell metabolic activity with respect to the bare samples (PEG$b$-PCL/PLLA). At $72 \mathrm{~h}$, the HCs cultured on PEG- $b$-PCL/ PLLA-10 samples showed a significantly higher metabolic activity with respect to all the other sample types, suggesting that the ZnO NPs, embedded in the polymeric matrix, may trigger an upregulation of proteoglycan synthesis, as already reported in the literature, even if in hypoxia conditions. ${ }^{75}$ On the other hand, the material roughness may also contribute to determine the chondrocyte behavior. However, it has been demonstrated that its role is more relevant when assessing the 
glycosaminoglycans and collagen formation for Ra values up to $230 \mathrm{~nm}^{76}$ Zinc deficiency has been correlated to cartilagerelated diseases; being involved in the antioxidant capacity of chondrocytes, its lack might inhibit cell proliferation. ${ }^{77,78}$ It has been demonstrated that zinc, even at low doses (lower than 0.5 $\mu \mathrm{M})$, can increase the proliferation of chondrocytes by $40-$ $50 \%$. $^{79}$

As for osteoblasts, piezoelectric composites may contribute to cartilage healing, while chondrocyte cells are exposed to stress. $^{68}$ The use of piezoelectric nanomaterials may thus lead to interesting applications in the field of cartilage tissue engineering, as recently shown for barium titanate. ${ }^{80 \text { " }}$

Safety issues may arise in relation to a possible release of $\mathrm{ZnO}$ from the polymeric matrix, although $\mathrm{ZnO}$ NPs represent one of the most relevant nanomaterials used in biomedical applications because of their interesting features, such as UV light absorption and antimicrobial properties. ${ }^{81,82}$ Toxicity has been mainly related to the particle size (diameter less than 50$\left.60 \mathrm{~nm},{ }^{83}\right)$, as well as concentration. ${ }^{84,85}$ Indeed, $\mathrm{Zn}^{2+}$ dissociated from $\mathrm{ZnO}$ could be associated with cytotoxic phenomena and oxidative stress conditions. However, $\mathrm{ZnO}$ NPs are highly sensitive toward phosphate ions, which can limit the concentration of free $\mathrm{Zn}^{2+}$ ions with the rapid precipitation of zinc phosphate, which can be transported to the liver for controlled recycling of the zinc ions. ${ }^{86}$

\section{CONCLUSIONS}

A novel nanocomposite ultrathin film based on a blend of PEG- $b$-PCL and PLLA, doped with different concentrations of $\mathrm{ZnO}$ NPs, was described. The PEG- $b$-PCL-PLLA blend showed a peculiar porous texture; the porosity decreased with the increase of $\mathrm{ZnO}$ NPs. Higher concentrations of NPs also implied larger roughness, piezoelectricity, stiffness, melting point, crystallinity, and a slower degradation rate.

The interaction between the different material formulations and mammalian cells was evaluated by means of cell models owing to the musculoskeletal apparatus, namely, fibroblasts, osteoblasts, myoblasts, and chondrocytes. All cell types showed a good viability on the different samples. Metabolic activity quantification over 3 days revealed no difference between samples concerning MG-63 osteoblasts, while the surface bioactivity of $\mathrm{ZnO}$ NPs, especially at high concentration (10 $\mathrm{mg} / \mathrm{mL}$ ), significantly affected the metabolic activity of fibroblasts, C2C12 myoblasts, and chondrocytes.

The bioactivity of the nanocomposite nanofilms also played a role in the formation of calcium deposits during osteoblasts differentiation, as well as in the formation of long myotubes during myoblast differentiation. A correspondence between $\mathrm{ZnO} \mathrm{NP}$ concentration and osteogenesis and myogenesis processes was found, suggesting an important role of NPs in mediating osteogenic and muscular differentiation on the proposed nanofilms. Future studies may also focus on the chondrogenic properties of this nanocomposite film, exploiting its piezoelectricity, to this purpose.

Overall, the results highlight the potential of the proposed nanofilm formulations for tissue regeneration and regenerative medicine applications.

\section{MATERIALS AND METHODS}

Nanofilm Fabrication. A blend solution $(150 \mu \mathrm{L})$ made of 25 $\mathrm{mg} / \mathrm{mL}$ of PEG- $b$-PCL (PEG average $M_{\mathrm{n}} \approx 5000$, PCL average $M_{\mathrm{n}} \approx$ 32,000 , Sigma-Aldrich) and $5 \mathrm{mg} / \mathrm{mL}$ of PLLA $\left(M_{\mathrm{w}}=101,000\right.$, Sigma-Aldrich) in dichloromethane was spin-coated over a glass substrate (diameter: $12 \mathrm{~mm}$ ) at $2000 \mathrm{rpm}$ for $20 \mathrm{~s}$ (acceleration 500 $\mathrm{rpm} / \mathrm{s})$.

$\mathrm{ZnO}$ nanopowder $(<100 \mathrm{~nm}$ particle size, Sigma-Aldrich) was added at different concentrations $(0.1,1$, and $10 \mathrm{mg} / \mathrm{mL})$ to the polymeric solution and sonicated for $1 \mathrm{~h}$ in an ultrasound bath. Finally, the solution was spin-coated with the same parameters reported above.

Characterization of Morphology and Thickness. The surface morphology was characterized by SEM (EVO MA15, Zeiss Instrument) imaging. Scans were performed by setting a beam voltage of $10 \mathrm{kV}$ and a probe current of $200 \mathrm{pA}$. For the EDX analysis, a dual beam microscope was used (FIB/SEM microscope, Helios, Hillsboro, OR, USA, NanoLab 600i, FEI, Hillsboro, OR, USA). To this purpose, a beam voltage of $15 \mathrm{kV}$, a current of $0.17 \mathrm{nA}$, and an acquisition time of $90 \mathrm{~s}$ were set.

For thickness measurements, a cut with tweezers was made at the center of each glass-supported nanofilm in order to measure the height profile across the scratch. Measurements were performed by means of a surface profiler (KLA-Tencor). Five independent samples were analyzed for each nanofilm type.

The evaluation of topography and roughness was performed by AFM (Veeco Innova Scanning Probe Microscope, Veeco Instruments Inc.). Scans were obtained in tapping mode by setting a $0.3 \mathrm{~Hz}$ scan frequency and scanning areas of $20 \times 20 \mu \mathrm{m}^{22}$ and $5 \times 5 \mu \mathrm{m}^{22}$ respectively. The cantilever had a nominal spring constant in the range $1.45-15.1 \mathrm{~N} / \mathrm{m}$ and a resonant frequency of $87-230 \mathrm{kHz}$. The Ra was measured as the average height of the centerline. Three images were acquired for each sample type, and three independent samples were analyzed for each nanofilm type.

For the FTIR analysis, each spectrum was acquired by using a Cary 660 FTIR spectrometer (Agilent Technologies). The scan resolution was $2 \mathrm{~cm}^{-1}$.

Contact Angle and Surface Energy Measurements. Contact angle measurements were performed on the ultrathin film surface by using the sessile drop method in air through a tensiometer (Theta Lite, Attension/Biolin Scientific). Drops of $3 \mu \mathrm{l}$ of deionized water (d$\mathrm{H}_{2} \mathrm{O}$ ), ethylene glycol, and hexane were placed on the sample surface, and data were acquired $5 \mathrm{~s}$ after the contact between the drop and the polymer surface. Three different points on the sample surface were analyzed for each sample, and three independent samples were analyzed for each sample type.

The analysis of the surface energy was performed after the evaluation of the contact angle of the mentioned polar and apolar liquids. By considering the van Oss-Chaudhury-Good theory which takes into account both polar and apolar components of surface energy, the complete Young's equation can be expressed as follows

$$
\gamma_{1 \mathrm{~s}}(1+\cos \vartheta)=2\left(\sqrt{\gamma_{1}^{\mathrm{LW}} \gamma_{\mathrm{S}}^{\mathrm{LW}}}+\sqrt{\gamma_{1}^{+} \gamma_{\mathrm{S}}^{-}}+\sqrt{\gamma_{1}^{-} \gamma_{\mathrm{S}}^{+}}\right)
$$

where $\theta$ is the measured contact angle, $\gamma_{\mathrm{ls}}$ is the surface tension of the liquid, $\gamma_{1}^{\mathrm{LW}}$ and $\gamma_{\mathrm{S}}^{\mathrm{LW}}$ are the Lifshitz-van der Waals components of surface energy, and $\bar{\gamma}+$ and $\bar{\gamma}-$ are the electron acid-base acceptor and donor components, which can be referred to both the solid and the liquid media. Therefore, resolving a $3 \times 3$ equation system, it is possible to obtain the energy parameters associated with solid surface $\left(\gamma_{S}^{+}, \gamma_{S}^{-}, \gamma_{S}^{\mathrm{LW}}\right)$. The parameters associated with the surface tension of liquids $\left(\gamma_{1}^{+}, \gamma_{1}^{-}, \gamma_{1}^{\mathrm{LW}}\right)$ are known from the literature. ${ }^{87,88}$ The surface energy $\gamma_{S}$ can be thus derived by solving the following equation

$$
\gamma_{\mathrm{s}}=\gamma_{\mathrm{s}}^{\mathrm{LW}}+2 \sqrt{\gamma_{\mathrm{S}}^{+} \gamma_{\mathrm{S}}}
$$

Piezoelectric Characterization. The piezoelectric properties were investigated by means of PFM (Icon Bruker AFM system), setting a scan frequency of $0.3 \mathrm{~Hz}$ and a scanning area of $5 \times 5 \mu \mathrm{m}^{2}$. A silicon probe with a $\mathrm{Pt}-\mathrm{Ir}$ coating (SCM-PIT), a measured spring constant of $1.72 \mathrm{~N} / \mathrm{m}$, a resonant frequency of $68.2 \mathrm{kHz}$, and a deflection sensitivity of $108 \mathrm{~nm} / \mathrm{V}$ was used. The amplitude and phase of the piezoelectric signals were acquired in the vertical direction via lock-in detection by applying to the tip an alternating current (ac) voltage of $10 \mathrm{~V}$ at a $15 \mathrm{kHz}$ frequency. Five specimens for each sample 
type were analyzed, and the average value of the piezoresponse amplitude $\left(d_{33}\right.$ piezoelectric coefficient $)$ in the PFM maps was calculated as follows

$$
\begin{aligned}
& d_{33}(\mathrm{~nm} / \mathrm{V})= \\
& \quad \frac{(\text { amplitude }(\text { in } V) \times \text { deflection sensitivity }(\mathrm{nm} / \mathrm{V}))}{(\text { vertical deflection gain }(16 x) \times \text { applied ac bias }(V))}
\end{aligned}
$$

Mechanical Characterization. The nanofilm mechanical properties were assessed by using the SIEBIMM test. ${ }^{89}$ Nanofilms were released in $\mathrm{d}-\mathrm{H}_{2} \mathrm{O}$ and collected on a prestretched ( $5 \%$ strain) polydimethylsiloxane (PDMS) stripe (10:1 as the mixing ratio). The samples were dried overnight prior to relaxing the PDMS substrate, thus producing the nanofilm buckling. An optical profiler (Leica DCM8) was used to analyze the buckling wavelength. $Z$-stacks (scan area: $254 \times 190 \mu \mathrm{m}^{2}$ ) were acquired, and data were converted into $2 \mathrm{D}$ images provided with a height-related grayscale to analyze the wavelength. Young's modulus was obtained as follows

$$
E=\frac{3\left(E_{\mathrm{PDMS}}\left(1-v_{\mathrm{PDMS}}^{2}\right)\right)}{\left(1-v_{\mathrm{P}}^{2}\right)}\left(\frac{\lambda}{2 \pi t}\right)
$$

where $E$ is the elastic modulus, $\nu$ is the Poisson ratio, $p$ is the subscript referring to the nanofilm, $\lambda$ is the wavelength of the wrinkles, and $t$ is the nanofilm thickness. In eq 2, we used an $E_{\mathrm{PDMS}}$ value of $1.8 \mathrm{MPa}$, a $\nu_{p}$ value of 0.36 , and a $\nu_{\text {PDMS }}$ value of $0.50 .{ }^{90}$

Degradation Tests. Nanofilm degradation was evaluated by incubating each sample type at $37{ }^{\circ} \mathrm{C}$ in phosphate-buffered saline (PBS) within an orbital agitator (711CT, Elettrofor). A cyclic agitation at $2 \mathrm{rpm}$ was imposed for the whole testing period. The nanofilm degradation kinetics was evaluated by monitoring the percentage of the dry weight loss overtime at different time points: 1 week, 2, 4, 8, and 16 weeks. Six independent samples for each nanofilm type were tested.

Differential Scanning Calorimetry. The thermal behavior of the different nanofilm formulations was investigated by differential scanning calorimetry (DSC, Setaram DSC 131). Each sample (2.5 $\mathrm{mg}$ ) was heated from -80 to $190{ }^{\circ} \mathrm{C}$ at a heating rate of $10^{\circ} \mathrm{C} / \mathrm{min}$. The samples were then immediately cooled to $-80{ }^{\circ} \mathrm{C}$ for $15 \mathrm{~min}$ after reaching the target temperature and then heated again from -80 to $190{ }^{\circ} \mathrm{C}$ at a heating rate of $10{ }^{\circ} \mathrm{C} / \mathrm{min}$. The material melting point was obtained from the second heating run, while crystallinity was calculated with reference to the enthalpy of fusion of PCL (139.5 J/ $\left.\mathrm{g},{ }^{91}\right)$. Each value reported was an average of three independent specimens for each nanofilm type.

Nanofilm Fabrication for in Vitro Experiments. For cell culture experiments, glass slides were previously modified through a silane surface functionalization to keep them adherent during the in vitro tests. First, the glass slides were treated with oxygen plasma (30 $\mathrm{s}, 50 \mathrm{~W}$ at $0.5 \mathrm{mbar})$. Then, they were immersed in trimethylchlorosilane (Sigma-Aldrich) for $15 \mathrm{~min}$. After washing with isopropanol alcohol, the glass slides were spin-coated with the different solutions used to obtain the different nanofilm types.

Before cell culture experiments, the nanofilms were coated with an ultrathin layer of collagen type I to favor cell adhesion according to a previous protocol. ${ }^{92}$ Briefly, a working solution $(\mathrm{pH}=7.2)$ of collagen type I from calf (Sigma-Aldrich) was prepared at a concentration of $15 \mu \mathrm{g} / \mathrm{mL}$ in PBS with $1 \%$ of pen/strep (P/S, Gibco). Each sample was UV-irradiated for $30 \mathrm{~min}$ before adding the working solution (1 $\left.\mathrm{mL} / \mathrm{cm}^{2}\right)$. Substrates were incubated for $6 \mathrm{~h}$ at $37^{\circ} \mathrm{C}$. Then, the collagen solution was removed, and a uniform liquid film was formed on the sample surface by gently agitating a drop of d- $\mathrm{H}_{2} \mathrm{O}$ on it $(100$ $\left.\mu \mathrm{L} / \mathrm{cm}^{2}\right)$. Then, all samples were kept at $37^{\circ} \mathrm{C}$ until the liquid was fully evaporated $(\sim 48 \mathrm{~h})$.

Cell Cultures. nHDFs (CC-2511, Lonza), human osteosarcoma cells (MG-63, ATCC-1427), murine skeletal myoblasts (C2C12, ATCC-1772), and HCs (Cell Applications Inc.) were used as cell models. nHDFs were cultured in growth medium consisting of highglucose Dulbecco's modified Eagle's medium (DMEM, SigmaAldrich) supplemented with $10 \%$ fetal bovine serum (FBS, Euro- clone) and $1 \% \mathrm{P} / \mathrm{S}$. Cells were seeded on the samples at a density of 25,000 cells $/ \mathrm{cm}^{2}$.

MG-63 cells were cultured in growth medium consisting of Minimum Essential Medium Eagle-Alpha Modification (MEM- $\alpha$, Sigma-Aldrich) supplemented with $10 \% \mathrm{FBS}$ and $1 \% \mathrm{P} / \mathrm{S}$. Cells were seeded on the samples at a density of 25,000 cells $/ \mathrm{cm}^{2}$. MG-63 differentiation was induced by switching the medium 2 days after seeding. The differentiation medium consisted of MEM- $\alpha$ supplemented with $10 \mathrm{mM} \beta$-glycerophosphate (Sigma-Aldrich), $100 \mathrm{nM}$ dexamethasone (Sigma-Aldrich), and $50 \mu \mathrm{M}$ L-ascorbic acid (SigmaAldrich). The differentiation medium was renewed every 2 days.

C2C12 cells were cultured in growth medium consisting of DMEM supplemented with $10 \% \mathrm{FBS}$ and $1 \% \mathrm{P} / \mathrm{S}$. Cells were seeded on the samples at a density of $25,000 \mathrm{cells} / \mathrm{cm}^{2}$. C2C12 differentiation was induced by switching the medium 2 days after seeding. The differentiation medium consisted of DMEM supplemented with $1 \%$ ITS (Sigma-Aldrich) and was renewed every day.

$\mathrm{HC}$ cells were cultured in growth medium consisting of $\mathrm{HC}$ Growth Medium (Cell Applications Inc.). Cells were seeded on the samples at a density of 25,000 cells $/ \mathrm{cm}^{2}$.

Viability and Metabolic Activity Assays. The interaction between cells and nanofilms was first assessed by means of the live/ dead viability/cytotoxicity Kit (Invitrogen) and the PrestoBlue (Invitrogen) assay. In the first case, the cells were washed with PBS $24 \mathrm{~h}$ after seeding and incubated with calcein and ethidium homodimer for $30 \mathrm{~min}$ at $37{ }^{\circ} \mathrm{C}$. Then, fluorescence images were acquired by means of an inverted microscope (Eclipse Ti, FITCTRITC filters, Nikon Corporation) equipped with a CCD camera (DS-5MC USB2, Nikon Corporation) to discriminate live cells (in green) from dead/necrotic ones (in red). For the PrestoBlue assay, at the desired time points $(24,48$, and $72 \mathrm{~h})$ the cells were incubated for $2 \mathrm{~h}$ with a $10 \%$ solution of the reagent in basal culture medium. The resulting supernatant was diluted (1:1) with medium, and fluorescence was measured with a microplate reader (Victor X3, PerkinElmer) at an excitation wavelength of $535 \mathrm{~nm}$ and an emission wavelength of $615 \mathrm{~nm}$. Three independent samples were analyzed for each sample type and for each time point.

Alizarin Red S Staining and Calcium Quantification. After 10 days of MG-63 cell differentiation, each sample was washed two times with PBS and then incubated with paraformaldehyde (4\%) for $30 \mathrm{~min}$ at room temperature. After washing two times with PBS, the samples were incubated with $2 \%$ wt. Then, the samples were stained with Alizarin Red S solution ( $\mathrm{pH}=4.1-4.3$, Merck) for $30 \mathrm{~min}$ in the dark and washed two times with $\mathrm{d}-\mathrm{H}_{2} \mathrm{O}$ to remove unspecific staining. Bright-field images were then acquired, and the amount of calcium was quantified by analyzing the density of the red-covered areas through ImageJ. The mineralization degree was also quantified by incubating the samples in a solution of $20 \%$ methanol (SigmaAldrich) and $10 \%$ acetic acid (Fisher Scientific) in d- $\mathrm{H}_{2} \mathrm{O}$. After 15 $\mathrm{min}$, the liquid was transferred into cuvettes, and the quantity of Alizarin red dissolved was read through a UV/VIS Lambda 45 spectrophotometer (PerkinElmer) at a wavelength of $450 \mathrm{~nm}$. Four independent samples were analyzed for each sample type.

C2C12 Staining and Assessment of Skeletal Muscle Cell Differentiation. After 5 days of $\mathrm{C} 2 \mathrm{C} 12$ cell differentiation, the samples were washed with PBS and incubated with paraformaldehyde (4\%) for $30 \mathrm{~min}$ at room temperature. Then, the samples were washed with PBS and incubated with phalloidin (Sigma-Aldrich) for $30 \mathrm{~min}$ to stain the myotube actin filaments. Fluorescence images were then acquired by using an inverted microscope. From these images, the myotube length and width were assessed by analyzing at least 50 myotubes for each sample type.

Statistical Analyses. Normal data were reported as average value \pm standard deviation, while non-normal data were displayed as box plots (2.5th-97.5th percentile), showing their median values. Values outside 2.5th and 97.5th percentiles were considered as outliers. Normal data were analyzed through a one-way ANOVA with Tukey's post-test, while non-normal data were analyzed using a KruskalWallis test and a Dunn's multiple comparison test (GraphPad Prism 
v6). Statistically significant differences among sample types were defined through a significance threshold set at $5 \%(* p<0.05)$.

\section{ASSOCIATED CONTENT}

\section{(s) Supporting Information}

The Supporting Information is available free of charge at https://pubs.acs.org/doi/10.1021/acsami.0c00154.

Results of the EDX analysis on the different samples and high-magnification SEM image of the ZnO NPs (PDF)

\section{AUTHOR INFORMATION}

\section{Corresponding Author}

Leonardo Ricotti - The BioRobotics Institute and Department of Excellence in Robotics \& AI, Scuola Superiore Sant'Anna, 56127 Pisa, Italy; 이이.org/0000-0001-8797-3742; Phone: +39050 883074; Email: leonardo.ricotti@ santannapisa.it

\section{Authors}

Lorenzo Vannozzi - The BioRobotics Institute and Department of Excellence in Robotics \& AI, Scuola Superiore Sant'Anna, 56127 Pisa, Italy

Pedro Gouveia - The BioRobotics Institute, Scuola Superiore Sant'Anna, 56127 Pisa, Italy; Tissue Engineering Research Group, Department of Anatomy \& Regenerative Medicine, Royal College of Surgeons in Ireland (RCSI), Dublin D02 YN77, Ireland

Pasqualantonio Pingue - NEST, Scuola Normale Superiore and CNR Istituto Nanoscienze, 56127 Pisa (PI), Italy

Claudio Canale - Department of Physics, University of Genova, 16146 Genova, Italy

Complete contact information is available at: https://pubs.acs.org/10.1021/acsami.0c00154

\section{Notes}

The authors declare no competing financial interest. No ethics approval was required for these experiments.

\section{ACKNOWLEDGMENTS}

The authors thank Carlo Filippeschi for his support during all the clean-room procedures and Dr. Francesca Pignatelli for her advices and support during the DSC analyses. This research was supported by the European Commission, through the project ADMAIORA (Advanced nanocomposite MAterIals fOr in situ treatment and ultRAsound-mediated management of osteoarthritis), funded in the Horizon 2020 framework grant number: 814413 (https://www.admaiora-project.com/).

\section{ABBREVIATIONS}

AFM, atomic force microscopy

DSC, differential scanning calorimetry

EDX, energy-dispersive X-ray spectroscopy

FTIR, Fourier transform infrared spectroscopy

NPs, nanoparticles

PDMS, polydimethylsiloxane

PEG- $b$-PCL, poly(ethylene glycol)-block-poly( $\varepsilon$-caprolactone) methyl ether

PEG- $b$-PCL/PLLA, nanofilm based on a blend of PEG- $b$ PCL and PLLA

PEG- $b$-PCL/PLLA-0.1, nanofilm based on a blend of PEG$b$-PCL and PLLA and doped with $0.1 \mathrm{mg} / \mathrm{mL}$ of $\mathrm{ZnO}$ NPs
PEG- $b$-PCL/PLLA-1, nanofilm based on a blend of PEG- $b$ PCL and PLLA and doped with $1 \mathrm{mg} / \mathrm{mL}$ of $\mathrm{ZnO}$ NPs

PEG- $b$-PCL/PLLA-10, nanofilm based on a blend of PEG$b$-PCL and PLLA and doped with $10 \mathrm{mg} / \mathrm{mL}$ of $\mathrm{ZnO}$ NPs PFM, Piezoresponse force microscopy

PLLA, poly(L-lactic acid)

SEM, scanning electron microscopy

SIEBIMM, strain-induced elastic buckling instability for mechanical measurements

$\mathrm{ZnO}$, zinc oxide

\section{REFERENCES}

(1) Fujie, T. Development of free-standing polymer nanosheets for advanced medical and health-care applications. Polym. J. 2016, 48, $773-780$.

(2) Fujie, T.; Okamura, Y.; Takeoka, S. Fabrication, properties and biomedical application of nanosheets. In Functional Polymer Films; Knoell, W., Advincula, R. C., Eds.; Wiley-VCH Verlag GmbH \& Co.: Weinheim, 2011; Chapter 29.

(3) Yang, H.; Su, M.; Li, K.; Jiang, L.; Song, Y.; Doi, M.; Wang, J. Preparation of patterned ultrathin polymer films. Langmuir 2014, 30, 9436-9441.

(4) Greco, F.; Zucca, A.; Taccola, S.; Mazzolai, B.; Mattoli, V. Patterned free-standing conductive nanofilms for ultraconformable circuits and smart interfaces. ACS Appl. Mater. Interfaces 2013, 5, 9461-9469.

(5) Borodina, T. N.; Grigoriev, D. O.; Andreeva, D. V.; Möhwald, H.; Shchukin, D. G. Polyelectrolyte multilayered nanofilms as a novel approach for the protection of hydrogen storage materials. ACS Appl. Mater. Interfaces 2009, 1, 996-1001.

(6) Jang, Y.; Park, S.; Char, K. Functionalization of polymer multilayer thin films for novel biomedical applications. Korean J. Chem. Eng. 2011, 28, 1149-1160.

(7) Vendra, V. K.; Wu, L.; Krishnan, S. Polymer Thin Films for Biomedical Applications. Nanotechnologies For the Life Sciences; WileyVCH Verlag GmbH \& Co, 2011.

(8) Van Tassel, P. R. Nanotechnology in medicine: nanofilm biomaterials. Yale J. Biol. Med. 2013, 86, 527-536.

(9) Takeoka, S.; Okamura, Y.; Fujie, T.; Fukui, Y. Development of biodegradable nanosheets as nanoadhesive plaster. Pure Appl. Chem. 2008, 80, 2259-2271.

(10) Jiang, B.; Barnett, JB; Li, B. Advances in polyelectrolyte multilayer nanofilms as tunable drug delivery systems. Nanotechnol. Sci. Appl. 2009, 2, 21-27.

(11) Zelikin, A. N. Drug releasing polymer thin films: new era of surface-mediated drug delivery. ACS Nano 2010, 4, 2494-2509.

(12) Vannozzi, L.; Ricotti, L.; Filippeschi, C.; Sartini, S.; Coviello, V.; Piazza, V.; et al. Nanostructured ultra-thin patches for ultrasoundmodulated delivery of anti-restenotic drug. Int. J. Nanomed. 2016, 11, 69.

(13) Vannozzi, L.; Iacovacci, V.; Menciassi, A.; Ricotti, L. Nanocomposite thin films for triggerable drug delivery. Expet Opin. Drug Deliv. 2018, 15, 509-522.

(14) Ozaydin-Ince, G.; Gleason, K. K.; Demirel, M. C. A stimuliresponsive coaxial nanofilm for burst release. Soft Matter 2011, 7, $638-643$.

(15) Van den Beucken, J. J. J. P.; Walboomers, X. F.; Vos, M. R. J.; Sommerdijk, N. A. J. M.; Nolte, R. J. M.; Jansen, J. A. Cyto- and histocompatibility of multilayered DNA-coatings on titanium. J. Biomed. Mater. Res. 2006, 77A, 202-211.

(16) Nichols, H. L.; Zhang, N.; Zhang, J.; Shi, D.; Bhaduri, S.; Wen, $\mathrm{X}$. Coating nanothickness degradable films on nanocrystalline hydroxyapatite particles to improve the bonding strength between nanohydroxyapatite and degradable polymer matrix. J. Biomed. Mater. Res. 2007, 82A, 373-382.

(17) Kam, K. R.; Walsh, L. A.; Bock, S. M.; Ollerenshaw, J. D.; Ross, R. F.; Desai, T. A. The effect of nanotopography on modulating 
protein adsorption and the fibrotic response. Tissue Eng. 2014, 20, $130-138$.

(18) Gribova, V.; Auzely-Velty, R.; Picart, C. Polyelectrolyte multilayer assemblies on materials surfaces: from cell adhesion to tissue engineering. Chem. Mater. 2012, 24, 854-869.

(19) Ventrelli, L.; Ricotti, L.; Menciassi, A.; Mazzolai, B.; Mattoli, V. Nanoscaffolds for guided cardiac repair: the new therapeutic challenge of regenerative medicine. J. Nanomater. 2013, 2013, 1.

(20) Boudou, T.; Crouzier, T.; Nicolas, C.; Ren, K.; Picart, C. Polyelectrolyte multilayer nanofilms used as thin materials for cell mechano-sensitivity studies. Macromol. Biosci. 2011, 11, 77-89.

(21) Li, M.; Mills, D. K.; Cui, T.; McShane, M. J. Cellular response to gelatin- and fibronectin-coated multilayer polyelectrolyte nanofilms. IEEE Trans. NanoBioscience 2005, 4, 170-179.

(22) Ricotti, L.; Taccola, S.; Pensabene, V.; Mattoli, V.; Fujie, T.; Takeoka, S.; Menciassi, A.; Dario, P. Adhesion and proliferation of skeletal muscle cells on single layer poly (lactic acid) ultra-thin films. Biomed. Microdevices 2010, 12, 809-819.

(23) Fujie, T.; Ricotti, L.; Desii, A.; Menciassi, A.; Dario, P.; Mattoli, V. Evaluation of substrata effect on cell adhesion properties using freestanding poly (L-lactic acid) nanosheets. Langmuir 2011, 27, 13173-13182.

(24) Yang, L.; Pan, F.; Zhao, X.; Yaseen, M.; Padia, F.; Coffey, P.; Freund, A.; Yang, L.; Liu, T.; Ma, X.; Lu, J. R. Thermoresponsive copolymer nanofilms for controlling cell adhesion, growth and detachment. Langmuir 2010, 26, 17304-17314.

(25) Ricotti, L.; Taccola, S.; Bernardeschi, I.; Pensabene, V.; Dario, P.; Menciassi, A. Quantification of growth and differentiation of $\mathrm{C} 2 \mathrm{C} 12$ skeletal muscle cells on PSS-PAH-based polyelectrolyte layer-by-layer nanofilms. Biomed. Mater. 2011, 6, 031001.

(26) Picollet-D’Hahan, N.; Gerbaud, S.; Kermarrec, F.; Alcaraz, J.-P.; Obeid, P.; Bhajun, R.; Guyon, L.; Sulpice, E.; Cinquin, P.; Dolega, M. E.; Wagh, J.; Gidrol, X.; Martin, D. K. The modulation of attachment, growth and morphology of cancerous prostate cells by polyelectrolyte nanofilms. Biomaterials 2013, 34, 10099-10108.

(27) Greco, F.; Fujie, T.; Ricotti, L.; Taccola, S.; Mazzolai, B.; Mattoli, V. Microwrinkled conducting polymer interface for anisotropic multicellular alignment. ACS Appl. Mater. Interfaces 2013, 5, 573-584.

(28) Pensabene, V.; Taccola, S.; Ricotti, L.; Ciofani, G.; Menciassi, A.; Perut, F.; Salerno, M.; Dario, P.; Baldini, N. Flexible polymeric ultrathin film for mesenchymal stem cell differentiation. Acta Biomater. 2011, 7, 2883-2891.

(29) Stevens, M. M.; George, J. H. Exploring and engineering the cell surface interface. Science 2005, 310, 1135-1138.

(30) Bettinger, C. J.; Langer, R.; Borenstein, J. T. Engineering substrate topography at the micro- and nanoscale to control cell function. Angew. Chem., Int. Ed. 2009, 48, 5406-5415.

(31) Podsiadlo, P.; Shim, B. S.; Kotov, N. A. Polymer/clay and polymer/carbon nanotube hybrid organic-inorganic multilayered composites made by sequential layering of nanometer scale films. Coord. Chem. Rev. 2009, 253, 2835-2851.

(32) Ventrelli, L.; Fujie, T.; Turco, S. D.; Basta, G.; Mazzolai, B.; Mattoli, V. Influence of nanoparticle-embedded polymeric surfaces on cellular adhesion, proliferation and differentiation. J. Biomed. Mater. Res. 2014, 102, 2652-2661.

(33) Uskokovíc, V.; Desai, T. A. Does translational symmetry matter on the micro scale? Fibroblastic and osteoblastic interactions with the topographically distinct poly $(\varepsilon$-caprolactone $) /$ hydroxyapatite thin films. ACS Appl. Mater. Interfaces 2014, 6, 13209-13220.

(34) Dash, T. K.; Konkimalla, V. B. Poly- $\varepsilon$-caprolactone based formulations for drug delivery and tissue engineering: a review. $J$. Controlled Release 2012, 158, 15-33.

(35) Wei, X.; Gong, C.; Gou, M.; Fu, S.; Guo, Q.; Shi, S.; Luo, F.; Guo, G.; Qiu, L.; Qian, Z. Biodegradable poly ( $\varepsilon$-caprolactone $)-$ poly (ethylene glycol) copolymers as drug delivery system. Int. J. Pharm. 2009, 381, 1-18.

(36) Yan, J.; Ye, Z.; Chen, M.; Liu, Z.; Xiao, Y.; Zhang, Y.; Zhou, Y.; Tan, W.; Lang, M. Fine tuning micellar core-forming block of poly (ethylene glycol)-block- poly ( $\varepsilon$-caprolactone) amphiphilic copolymers based on chemical modification for the solubilization and delivery of doxorubicin. Biomacromolecules 2011, 12, 2562-2572.

(37) Deng, H.; Liu, J.; Zhao, X.; Zhang, Y.; Liu, J.; Xu, S.; et al. PEGb-PCL copolymer micelles with the ability of $\mathrm{pH}$-controlled negativeto-positive charge reversal for intracellular delivery of doxorubicin. Biomacromolecules 2014, 15, 4281-4292.

(38) Kutikov, A. B.; Song, J. Biodegradable PEG-based amphiphilic block copolymers for tissue engineering applications. ACS Biomater. Sci. Eng. 2015, 1, 463-480.

(39) Xia, T.; Kovochich, M.; Liong, M.; Mädler, L.; Gilbert, B.; Shi, H.; Yeh, J. I.; Zink, J. I.; Nel, A. E. Comparison of the mechanism of toxicity of zinc oxide and cerium oxide nanoparticles based on dissolution and oxidative stress properties. ACS Nano 2008, 2, 21212134.

(40) Dodds, J. S.; Meyers, F. N.; Loh, K. J. Piezoelectric characterization of PVDF-TrFE thin films enhanced with $\mathrm{ZnO}$ nanoparticles. IEEE Sens. J. 2012, 12, 1889-1890.

(41) Ricotti, L.; Fujie, T.; Vazão, H.; Ciofani, G.; Marotta, R.; Brescia, R.; Filippeschi, C.; Corradini, I.; Matteoli, M.; Mattoli, V.; Ferreira, L.; Menciassi, A. Boron nitride nanotube-mediated stimulation of cell co-culture on micro-engineered hydrogels. PloS One 2013, 8, No. e71707.

(42) Na, Y.-H.; He, Y.; Shuai, X.; Kikkawa, Y.; Doi, Y.; Inoue, Y. Compatibilization effect of poly ( $\varepsilon$-caprolactone)-b-poly (ethylene glycol) block copolymers and phase morphology analysis in immiscible poly (lactide)/poly ( $\varepsilon$-caprolactone) blends. Biomacromolecules 2002, 3, 1179-1186.

(43) Ciofani, G.; Ricotti, L.; Mattoli, V. Preparation, characterization and in vitro testing of poly (lactic-co-glycolic) acid/barium titanate nanoparticle composites for enhanced cellular proliferation. Biomed. Microdevices 2011, 13, 255-266.

(44) Asghari, M.; Sheikh, M.; Dehghani, M. Comparison of $\mathrm{ZnO}$ nanofillers of different shapes on physical, thermal and gas transport properties of PEBA membrane: experimental testing and molecular simulation. J. Chem. Technol. Biotechnol. 2018, 93, 2602-2616.

(45) Prajitno, D. H.; Maulana, A.; Syarif, D. G. Effect of surface roughness on contact angle measurement of nanofluid on surface of stainless steel 304 by sessile drop method. J. Phys.: Conf. Ser. 2016, 739, 012029.

(46) Dai, X.; et al. Attenuating immune response of macrophage by enhancing hydrophilicity of Ti surface. J. Nanomater. 2015, 2015, 1.

(47) Li, B.; Xie, J.; Yuan, Z.; Jain, P.; Lin, X.; Wu, K.; Jiang, S. Mitigation of inflammatory immune responses with hydrophilic nanoparticles. Angew. Chem., Int. Ed. Engl. 2018, 57, 4527-4531.

(48) Van Oss, C. J.; Good, R. J.; Chaudhury, M. K. Additive and Nonadditive Surface Tension Components and the Interpretation of Contact Angles. Langmuir 1988, 4, 884-891.

(49) Ajami-Henriquez, D.; et al. Evaluation of cell affinity on poly (L-lactide) and poly ( $\varepsilon$-caprolactone) blends and on PLLA-b-PCL diblock copolymer surfaces. J. Biomed. Mater. Res. 2008, 87, 405-417.

(50) Roh, S. C.; Choi, E. Y.; Choi, Y. S.; Kim, C. K. Characterization of the surface energies of functionalized multi-walled carbon nanotubes and their interfacial adhesion energies with various polymers. Polymer 2014, 55, 1527-1536.

(51) Trino, L. D.; Dias, L. F. G.; Albano, L. G. S.; Bronze-Uhle, E. S.; Rangel, E. C.; Graeff, C. F. O.; Lisboa-Filho, P. N. Zinc oxide surface functionalization and related effects on corrosion resistance of titanium implants. Ceram. Int. 2018, 44, 4000-4008.

(52) Yin, G.; et al. Bio-compatible poly (ester-urethane)s based on PEG-PCL-PLLA copolymer with tunable crystallization and biodegradation properties. RSC Adv. 2015, 5, 79070-79080.

(53) Vijayakumar, S.; Vaseeharan, B. Antibiofilm, anti cancer and ecotoxicity properties of collagen based $\mathrm{ZnO}$ nanoparticles. Adv. Powder Technol. 2018, 29, 2331-2345.

(54) Shankar, S.; Wang, L.-F.; Rhim, J.-W. Incorporation of zinc oxide nanoparticles improved the mechanical, water vapor barrier, UV-light barrier, and antibacterial properties of PLA-based nanocomposite films. Mater. Sci. Eng. C 2018, 93, 289-298. 
(55) Tandon, B.; Blaker, J. J.; Cartmell, S. H. Piezoelectric materials as stimulatory biomedical materials and scaffolds for bone repair. Acta Biomater. 2018, 73, 1-20.

(56) Halperin, C.; Mutchnik, S.; Agronin, A.; Molotskii, M.; Urenski, P.; Salai, M.; et al. Piezoelectric effect in human bones studied in nanometer scale. Nano Lett. 2004, 4, 1253-1256.

(57) Whulanza, Y.; Battini, E.; Vannozzi, L.; Vomero, M.; Ahluwalia, A.; Vozzi, G. Electrical and mechanical characterisation of single wall carbon nanotubes-based composites for tissue engineering applications. J. Nanosci. Nanotechnol. 2013, 13, 188-197.

(58) Díez-Pascual, A.; Díez-Vicente, A. Poly (3-hydroxybutyrate)/ $\mathrm{ZnO}$ bionanocomposites with improved mechanical, barrier and antibacterial properties. Int. J. Mol. Sci. 2014, 15, 10950-10973.

(59) Taccola, S.; Pensabene, V.; Fujie, T.; Takeoka, S.; Pugno, N. M.; Mattoli, V. On the injectability of free-standing magnetic nanofilms. Biomed. Microdevices 2017, 19, 51.

(60) Burg, K.; Orr, D. An overview of bioresorbable materials. Degradation Rate of Bioresorbable Materials: Prediction and Evaluation; Elsevier, 2008; p 1 .

(61) Okamoto, M.; John, B. Synthetic biopolymer nanocomposites for tissue engineering scaffolds. Prog. Polym. Sci. 2013, 38, 14871503

(62) Awad, S.; Chen, H.; Chen, G.; Gu, X.; Lee, J. L.; Abdel-Hady, E.; et al. Free volumes, glass transitions, and cross-links in zinc oxide/ waterborne polyurethane nanocomposites. Macromolecules 2011, 44, $29-38$.

(63) Sabir, M. I.; Xu, X.; Li, L. A review on biodegradable polymeric materials for bone tissue engineering applications. J. Mater. Sci. 2009, 44, 5713-5724.

(64) Askadskii, A.; Popova, M.; Matseevich, T.; Kurskaya, E. The Influence of the degree of crystallinity on the glass transition temperature of polymers. Adv. Mater. Res. 2014, 864-867, 751-754. (65) Maschhoff, P. M.; Geilich, B. M.; Webster, T. J. Greater fibroblast proliferation on an ultrasonicated $\mathrm{ZnO} / \mathrm{PVC}$ nanocomposite material. Int. J. Nanomed. 2013, 9, 257.

(66) Wang, Y.; Deng, H.; Huangfu, C.; Lu, Z.; Wang, X.; Zeng, X.; He, H.; Rao, H. Research of protein adsorption on the different surface topography of the zinc oxide. Surf. Interface Anal. 2015, 47, $245-252$.

(67) Mauney, J. R.; Sjostorm, S.; Blumberg, J.; Horan, R.; O'Leary, J. P.; Vunjak-Novakovic, G.; et al. Mechanical stimulation promotes osteogenic differentiation of human bone marrow stromal cells on 3D partially demineralized bone scaffolds in vitro. Calcif. Tissue Int. 2004, 74, 458-468.

(68) Rajabi, A. H.; Jaffe, M.; Arinzeh, T. L. Piezoelectric materials for tissue regeneration: A review. Acta Biomater. 2015, 24, 12-23.

(69) Genchi, G. G.; Sinibaldi, E.; Ceseracciu, L.; Labardi, M.; Marino, A.; Marras, S.; De Simoni, G.; Mattoli, V.; Ciofani, G. Ultrasound-activated piezoelectric $\mathrm{P}$ (VDF-TrFE)/boron nitride nanotube composite films promote differentiation of human SaOS-2 osteoblast-like cells. Nanomed. Nanotechnol. 2018, 14, 2421-2432.

(70) Ohtsuki, C.; Kamitakahara, M.; Miyazaki, T. Bioactive ceramicbased materials with designed reactivity for bone tissue regeneration. J. R. Soc. Interface 2009, 6, S349-S60.

(71) Sahmani, S.; Saber-Samandari, S.; Shahali, M.; Joneidi Yekta, H.; Aghadavoudi, F.; Montazeran, A. H.; et al. Mechanical and biological performance of axially loaded novel bio-nanocomposite sandwich plate-type implant coated by biological polymer thin film. $J$. Mech. Behav. Biomed. Mater. 2018, 88, 238-250.

(72) Cheng, A.; Cohen, D. J.; Boyan, B. D.; Schwartz, Z. Lasersintered constructs with bio-inspired porosity and surface micro/ nano-roughness enhance mesenchymal stem cell differentiation and matrix mineralization in vitro. Calcif. Tissue Int. 2016, 99, 625-637.

(73) Vannozzi, L.; Ricotti, L.; Santaniello, T.; Terencio, T.; OropesaNunez, R.; Canale, C.; Borghi, F.; Menciassi, A.; Lenardi, C.; Gerges, I. 3D porous polyurethanes featured by different mechanical properties: Characterization and interaction with skeletal muscle cells. J. Mech. Behav. Biomed. Mater. 2017, 75, 147-159.
(74) Trujillo, S.; Lizundia, E.; Vilas, J. L.; Salmeron-Sanchez, M. PLLA/ZnO nanocomposites: Dynamic surfaces to harness cell differentiation. Colloids Surf. B Biointerfaces 2016, 144, 152-160.

(75) Mirza, E. H.; Pan-Pan, C.; Wan Ibrahim, W. M. A. B.; Djordjevic, I.; Pingguan-Murphy, B. Chondroprotective effect of zinc oxide nanoparticles in conjunction with hypoxia on bovine cartilagematrix synthesis. J. Biomed. Mater. Res., Part A 2015, 103, 3554-3563.

(76) Kosorn, W.; Sakulsumbat, M.; Lertwimol, T.; Thavornyutikarn, B.; Uppanan, P.; Chantaweroad, S.; Janvikul, W. Chondrogenic phenotype in responses to poly ( $\varepsilon$-caprolactone) scaffolds catalyzed by bioenzymes: effects of surface topography and chemistry. J. Mater. Sci. Mater. Med. 2019, 30, 128.

(77) Huang, T.-C.; Chang, W.-T.; Hu, Y.-C.; Hsieh, B.-S.; Cheng, H.-L.; Yen, J.-H.; Chiu, P.-R.; Chang, K.-L. Zinc protects articular chondrocytes through changes in Nrf2-mediated antioxidants, cytokines and matrix metalloproteinases. Nutrients 2018, 10, 471.

(78) Kim, J.-H.; et al. Regulation of the catabolic cascade in osteoarthritis by the zinc-ZIP8-MTF1 axis. Cell 2014, 156, 730-743.

(79) Rodríguez, J. P.; Rosselot, G. Effects of zinc on cell proliferation and proteoglycan characteristics of epiphyseal chondrocytes. J. Cell. Biochem. 2001, 82, 501-511.

(80) Jacob, J.; More, N.; Mounika, C.; Gondaliya, P.; Kalia, K.; Kapusetti, G. Smart Piezoelectric Nanohybrid of Poly (3-hydroxybutyrate-co-3-hydroxyvalerate) and Barium Titanate for Stimulated Cartilage Regeneration. ACS Appl. Bio Mater. 2019, 2, 4922-4931.

(81) Laurenti, M.; Cauda, V. $\mathrm{ZnO}$ nanostructures for tissue engineering applications. Nanomaterials 2017, 7, 374.

(82) Iswarya, A.; Vaseeharan, B.; Anjugam, M.; Ashokkumar, B.; Govindarajan, M.; Alharbi, N. S.; Kadaikunnan, S.; Khaled, J. M.; Benelli, G. Multipurpose efficacy of $\mathrm{ZnO}$ nanoparticles coated by the crustacean immune molecule $\beta$-1, 3-glucan binding protein: toxicity on HepG2 liver cancer cells and bacterial pathogens. Colloids Surf. B Biointerfaces 2017, 158, 257-269.

(83) Sirelkhatim, A.; Mahmud, S.; Seeni, A.; Kaus, N. H. M.; Ann, L. C.; Bakhori, S. K. M.; Hasan, H.; Mohamad, D. Review on zinc oxide nanoparticles: antibacterial activity and toxicity mechanism. NanoMicro Lett. 2015, 7, 219-242.

(84) Syama, S.; Sreekanth, P. J.; Varma, H. K.; Mohanan, P. V. Zinc oxide nanoparticles induced oxidative stress in mouse bone marrow mesenchymal stem cells. Toxicol. Mech. Methods 2014, 24, 644-653.

(85) Liu, J.; Kang, Y.; Yin, S.; Song, B.; Wei, L.; Chen, L.; Shao, L. Zinc oxide nanoparticles induce toxic responses in human neuroblastoma SHSY5Y cells in a size-dependent manner. Int. J. Nanomed. 2017, 12, 8085

(86) Herrmann, R.; García-García, F. J.; Reller, A. Rapid degradation of zinc oxide nanoparticles by phosphate ions. Beilstein J. Nanotechnol. 2014, 5, 2007.

(87) Van Oss, C. J.; Chaudhury, M. K.; Good, R. J. Interfacial Lifshitz-van der Waals and polar interactions in macroscopic systems. Chem. Rev. 1988, 88, 927-941.

(88) Aronov, D.; Rosenman, G. Surface energy modification by electron beam. Surf. Sci. 2007, 601, 5042-5049.

(89) Stafford, C. M.; Harrison, C.; Beers, K. L.; Karim, A.; Amis, E. J.; VanLandingham, M. R.; Kim, H.-C.; Volksen, W.; Miller, R. D.; Simonyi, E. E. A buckling-based metrology for measuring the elastic moduli of polymeric thin films. Nat. Mater. 2004, 3, 545 .

(90) Farah, S.; Anderson, D. G.; Langer, R. Physical and mechanical properties of PLA, and their functions in widespread applications-A comprehensive review. Adv. Drug Delivery Rev. 2016, 107, 367-392.

(91) Qipeng, G.; Groeninckx, G. Crystallization kinetics of poly (e caprolactone) in miscible thermosetting polymer blends of epoxy resin and poly (e-caprolaetone). J. Polym. 2001, 42, 8647-8655.

(92) Dupont-Gillain, C. C.; Pamula, E.; Denis, F. A.; De Cupere, V. M.; Dufrêne, Y. F.; Rouxhet, P. G. Controlling the supramolecular organisation of adsorbed collagen layers. J. Mater. Sci. Mater. Med. 2004, 15, 347-353. 